\title{
The Integration of Libraries and Academic Computing at Columbia: New Opportunities for Internal and External Collaboration
}

\author{
PATRICIA RENFRO \\ Columbia University, New York, NY, USA (retired) \\ JAMES G. NEAL \\ Columbia University, New York, NY, USA
}

\begin{abstract}
Over the past decade, the libraries and academic computing units at Columbia have been brought together to form a new information services organization. This article will trace the history and current state of IT and library relationships at Columbia University. The expanding collaboration among academic computing services, their deeper partnership and integration with library programs, the working relationship with campus administrative computing, and participation in national and international projects will be described and evaluated.
\end{abstract}

KEYWORDS libraries, academic computing, research instruction

The academic library is being driven by five fundamental shifts. Primal innovation: creativity as an essential component of our organizational and individual DNA. Radical collaboration: new, drastic, sweeping and energetic combinations across and outside libraries. Deconstruction: taking apart traditional axioms and norms, removing the incoherence of current concepts and models, and evolving new approaches and styles. Survival: persistence and adaptation which focuses more on the "human" objectives of our users, that is success, productivity, progress, relationships, experiences, and impact. Particularism: deep specialization and niche responsibilities in the face of rampant shared and open resources. How do we respond to these revolutionary trends through our shifting geography, our essential expertise, and our advocacy of the public interest?

Address correspondence to Patricia Renfro, 11 East Princeton Rd., Bala Cynwyd, PA 19004, USA. E-mail: pr339@columbia.edu 
The Columbia University Libraries/Information Services are responding to these extraordinary challenges through strategic investments in content, technology, tools, space, and people. And one important component of change has been the evolution of a hybrid organizational structure, integrating key elements of the research library and university technology services.

The basis of any organization is individuals and groups carrying out roles and working together to achieve shared objectives within a formal structure and with established processes. Organizations define the systems through which goals and priorities are established, decisions are made, resources are allocated, power is wielded, and plans are accomplished. They determine the degree to which administrative responsibility and authority are distributed and shared, operations and procedures are integrated and flexible, and policies and standards are designed and enforced.

Organizational models focus on a set of parameters defined by: centralization and decentralization, hierarchy and adhocracy, bureaucracy and distribution, simplicity and complexity, formality and informality, administration and entrepreneurship, authority and collaboration. They can be viewed, among many characteristics, in terms of layers and rigidity of structure, direction and effectiveness of information flow, sources and impact of leadership, participation in decision making, freedom of action, and levels of ambiguity. Particularly important are the health of the industry, the level of competition, the speed of technological change, the extent of globalization, the degree of professionalization in the field, and the rapidity of new knowledge creation. These have been critical considerations as the Libraries' organization has expanded.

Libraries have struggled to distribute authority, integrate key operations, breakdown bureaucratic processes, achieve less rigidity in structure, promote more cooperation across units, and build more matrix-type approaches to the work. As a result, centralized planning and resource allocation systems coexist with broadly distributed and loosely coupled structures and an expanding array of maverick units like research centers and entrepreneurial enterprises.

Columbia University was an early integrator of information technology and information services functions under a single administrator. By the early 1970s, all computing and telecommunications areas were administered by a $\mathrm{CIO}$, reporting to the executive vice president for academic affairs. By the mid 1980s, this structure was expanded to include the University Libraries, but now under the direction of a vice president and university librarian. By 1989, the pendulum had swung back in the other direction, with administrative computing and telephone services moving to an administrative vice president. Academic computing, network services, electronic mail, electronic classroom support, computer labs, videoconferencing, security authorization and authentication, the data center, technology training, helpdesk and the libraries continued to report to the librarian, and the unit was expanded over 
time to include electronic publishing, digital library, instructional technology, and research computing units. In 2004, another reorganization pushed all administrative, network, and telecommunications technologies under a new CIO position. Academic computing and the libraries were assigned to the university librarian.

In 2007 the Columbia Libraries and Information Services implemented a rationalized organizational structure, creating four administrative groups under the direction of the Vice President for Information Services and University Librarian. One group is responsible for administrative services, including budget and finance, facilities and building projects, and human resources. A second group, Bibliographic Services and Collection Development, includes units responsible for serials acquisitions, electronic resources, monograph acquisitions, copy and original cataloging, database maintenance, metadata services, collection development, and the offsite shelving facility. A third group, Collections and Services, includes three multidisciplinary library divisions for history and humanities, social sciences, and sciences and engineering; the global and distinctive collections in the Starr East Asian Library, the Avery Architecture and Fine Arts Library, the Rare Book and Manuscript Library, the Global Resources Program, and the Burke Theology Library; and Access Services including circulation, interlibrary loan/document delivery, collection management, reserves, and building security. The fourth group, Digital Programs and Technology Services, includes the Libraries Digital Program, the Library Information Technology Office, the Preservation and Digital Conversion Division, the Center for New Media Teaching and Learning, the Center for Digital Research and Scholarship, and the Copyright Advisory Office. The latter two Centers were created in 2007 at the time of the reorganization in order to focus on unmet needs in the University.

In the past decade the way faculty and students access information, the way they in fact use information and the way they need to manage that information, have been transformed by technology. At the Columbia Libraries it became increasingly clear that academic computing would be the foundation of new library services and that the integration of academic computing units and skills into the traditional library organization was critical to our ongoing success. Consequently the development of the Digital Programs group, and its working relationships with the more traditional parts of the Columbia Libraries, became a key strategic focus. In total Digital Programs has a staff of approximately 110 FTEs who together are breaking new ground, experimenting with new technologies and piloting new services, while at the same time addressing the very traditional mission of libraries to preserve information for the use of current and future generations.

Critical to the success of the new Digital Programs group was a major change in mission for the Library Information Technology Office (LITO). The Libraries continue to have a close working relationship with the central campus computing organization and rely on them for management of the 
network, for capacity in the central data center and for the administration of the course management systems, as well as for the administration of enterprise systems such as e-mail. However, in recent years central computing found itself increasingly focused on support for administrative computing and it became clear that the Libraries needed more control of its technology infrastructure. Consequently LITO's role and staffing were expanded starting in 2007 in order to provide full technology services and support across the organization. LITO runs the Libraries' long-term digital storage system, which underpins the work of the Library's Digital Program and is also critical to the University's institutional repository, Academic Commons. LITO also manages Novell storage to support internal digital production activity and maintains a number of online services such as a WordPress platform, used by all Digital Programs and many library units. The Center for Digital Scholarship was established with a clear understanding that most of its technical support would come from LITO.

The new library organization is by nature highly collaborative. Where possible the group aims to select platforms that will be of broad use and will therefore provide a shared and efficient infrastructure. Consequently the implementation of the Libraries' Fedora system was a high priority and a joint effort with programmers working across units to share skills and expertise. Some units, by the nature of their programs, work in tandem: the Center for Digital Research and the Copyright Advisory Office together educate the university community about scholarly communication and copyright issues; the Libraries Digital Programs Division and Preservation's Digital Conversion group plan and conduct digital conversion projects together, calling also on the expertise of metadata specialists in Technical Services; the Library Information Technology Office works with the Libraries Digital Program and the Center for Digital Research on digital archiving. Collaborations between these groups and library staff continue to expand and develop: curators frequently work with the Center for New Media staff to develop online environments that allow students to explore special collections resources; public services staff work with library technology staff to offer subject-focused Digital Commons facilities to undergraduate and graduate students; library liaisons introduce researchers to the value of deposit in the repository, and may tell them about journal, conference and video services offered by the Center for Digital Scholarship. Collaborations within the University, are also common and growing as the Digital Programs group develops and strengthens programs: researchers now regularly look to the Center for New Media to partner on large federal grant applications; schools and academic departments are increasingly aware of the value of the institutional repository for long term archiving; and the University's Office of Research has called on the Libraries for help in addressing new NIH and NSF requirements. The list of collaborations is lengthy and perhaps best illustrated by an overview of the services developed during the past decade. These fall into three major 
categories: student computing services, instructional support, and research support.

The need to repurpose library space to meet the changing practices of students has been apparent at Columbia for well over a decade, and general University-wide computing labs were installed in the Butler (humanities) and Lehman (social sciences) libraries well before the Information Commons movement took hold in research libraries across the country. Rather than replicate the standard, broad-based information commons model, we decided that Columbia would be better served by a series of subject-focused digital commons. These would serve upper level undergraduates and graduate students, and provide high-end hardware and software targeted at the needs of specific disciplines. Today three major digital centers are in operation: the Digital Humanities Center, focusing on textual analysis, image scanning and editing, digital video editing, etc.; the Digital Social Science Center focusing on the use of numeric and geospatial data; and the Digital Science Center focusing on scientific analysis and visualization. The Centers are staffed by public services librarians with appropriate skills and subject knowledge, supported by the Library Technology Office which plans the installations and upgrades and fully manages two of the centers and shares support of one with the central IT organization. Indications so far are that these subject-focused centers, with the critical combination of staff expertise and hardware and software, are meeting a critical campus need. Other specialized academic computing centers are planned and will follow the successful model of the Music Library where workstations are outfitted with high-end audio editing, music notation and related applications, and Music librarians provide expert consultation services.

Columbia's Center for New Media Teaching and Learning (CCNMTL) was established in 1999 "to enhance teaching and learning through the purposeful use of new media and technology." The word "purposeful" is key here: new learning environments designed by the Center are in a continuous loop of evaluation, assessment, and improvement. CCNMTL partners with faculty to provide a range of services from basic course Web site management to advanced project development. Columbia's central IT organization runs the hardware and software for Columbia's legacy course management system and its in-process Sakai implementation, but all faculty support, and training for departmental administrative staff, is provided by CCNMTL.

Using the course management systems as a base for managing courses and registrations, CCNMTL promotes complementary third party best-ofbreed collaborative learning tools such as a multi-author course blogging service called EdBlogs, built on the Library Information Technology Office's implementation of WordPress. Faculty can also enable a wiki for any course using the Columbia Wikispaces services, and can upload audio and video to the Columbia iTunes U and YouTube EDU media platforms, both managed by the Center. Workshops, a drop-in Faculty Support Center located in Butler 
Library, and the "Tools" and "EnhancED" sections of the Center's Web site, combine to offer a variety of avenues for assistance and support.

The other major focus of the Center's work, advanced project management, partners Center staff with faculty across campus to develop online teaching environments for specific courses or to fulfill a component of a research grant. A few examples here can only touch on the range of projects, which are best understood by visiting the Web site: http://ccnmtl. columbia.edu/portfolio/.

MySmileBuddy is an iPad tool supported by NIH and developed with Columbia's School of Dental Medicine to allow social workers and dental professionals to work with families on preventive oral health care. This is one of a number of projects in the Center's Triangle Initiative, which aims to develop digital tools to extend faculty research, transform the education of human service professionals, and provide benefits to communities in need. Using the Triangle approach CCNMTL has become a sought for partner in research grants across the University, and external funding of this kind now makes up a significant percentage of the Center's operating budget.

The Global Master's Degree in Development Practice, funded by the MacArthur Foundation, matriculated its first class of students at Columbia in fall 2009. CCNMTL supports this Master's degree program with a range of customized tools that enable synchronous and asynchronous collaboration among the participants in shared courses taught simultaneously at approximately 15 universities around the world.

Mapping the African American Past is a public Web site created by CCNMTL to enhance the appreciation and study of significant sites and moments in the history of African Americans in New York from the early 17th-century through the recent past. The Web site is a geographic learning environment, developed with the assistance of the Library's geographic information services librarians. It enables students, teachers, and visitors to browse a multitude of locations in New York and read encyclopedic profiles of historical people and events associated with these locations.

The Black Radical Archive, an online repository for a course on Black Radicalism, represents a unique platform for engaging students in the curation of rare archival materials. It houses images of archival materials that the professor and his students selected from the Library's Rare Book and Manuscript Library. Archivists worked closely with students in this course to enable them to explore unprocessed as well as processed black history collections, and select items to describe and record themselves with digital images. In addition, selected audio recordings, and manuscript items, critical to the course, were digitized on request by the Preservation and Digital Conversion division.

Both Mapping the African American Past and the Black Radical Archive are projects developed as part of CCNMTL's Digital Bridges Initiative. This strategic initiative explores the creation of learning environments using 
persistent high-quality digital resources. It is particularly in the Digital Bridges projects that the Center's organizational base within the Libraries can be seen to be most valuable. Working closely with curators and librarian liaisons in humanities, social sciences and sciences, the Center has been able to identify new opportunities to work with faculty and unique collections and to use innovative technology to create ways to look at and integrate information resources into classroom teaching. Curators and librarians bring their knowledge of the collections, their understanding of the metadata necessary for good digital retrieval, and their familiarity with the work and interests of faculty. The connections here have often opened doors and resulted in new ways of exposing collections to students.

Although the bulk of technical support for instruction at Columbia comes from the Center for New Media, the Libraries Digital Program and Preservation and Digital Conversion groups also work directly to support specific teaching needs. A faculty member who had regularly used the New York Real Estate Record and Builders' Guide in his historic conservation course asked that it be digitized to provide better access and searchability for his students. As a result 110 dense volumes of real estate transactions are now accessible online to the general public and researchers worldwide. In the case of a fragile and at risk Tibetan newspaper, the Tibet Mirror, the primary motivation for digitization was conservation, but faculty also noted the value of making the digitized text accessible for students to examine, read, and translate since this paper chronicles dramatic social and political transformations in Tibet. Through the efforts of the Tibetan Studies Librarian the Columbia issues have been significantly augmented with equally rare issues from three other collections, so that $70 \%$ of the full run of the paper is now online. Faculty interest in using digitized material for instruction or research is an important factor in helping to set priorities for digitization.

The success of the Center for New Media and its impact on instruction at Columbia was so clearly evident by 2007 that the Libraries decided to create a Center for Digital Research and Scholarship (CDRS), to provide a comparable set of services in support of research. At the same time, recognizing that intellectual property issues are fundamental to the dissemination of research, the Libraries established a Copyright Advisory Office (CAO) to work closely with all Digital Programs and Libraries units.

Following discussions with scholars and researchers across campus it became apparent that it would be possible to develop a suite of scalable services to meet a common set of needs. The robust list of services now described on the Center's Web site represents an intense period of experimentation and development during the past four years (http://cdrs.columbia. edu/cdrsmain/). The Center administers the university's institutional repository, offers a number of types of publication services, conference and video services, and provides collaboration tools in form of the WikiScholars service. Through its Web site and regular presentations across campus, the 
Copyright Advisory Office actively promotes an understanding of copyright issues.

In contrast to the free instructional support services offered by the Center for New Media, the Center for Digital Research has found it necessary to develop a range of free and for fee services. The group's video team, as the primary video service on campus, charges for capture, editing, etc. Although this is not a cost recovery service, the income helps to provide a stable and robust service. Other services, such as the journal hosting service and conference support service offer graduated levels of support from a free barebones set up to a premier offering, which includes significant amounts of Web design. The journals hosting service has been particularly attractive to the Law School where the advantages of having a consistently administered publication framework that can be easily managed through annual changes of student editorial staff has been very clear. Workshops held by Center staff and the Director of the Copyright Advisory Office have provided critical education in intellectual property issues for student journal editors. Although most of the journals currently in production are student run, the Center is now also publishing its first peer-reviewed faculty edited journal, Tremors. Working with the editor and founder of the journal, the Center's Director was able to frame an Open Access business model for this title, and will be monitoring and analyzing this model for the benefit of colleagues in the scholarly publishing community. The Scholarly Communication program, which educates the Columbia community about changes taking place within the scholarly communication system, is a major focus of the Center for Digital Research and works in tandem with the Director of the Copyright Advisory Office.

Other innovative publishing projects have included creating a digital version of a scholarly print monograph simultaneously published by Fordham University Press in a traditional paper version. The Center also developed a solution for an encyclopedic work on film that was initially planned as a print publication but proved to be a better fit for a Wikipedia-like solution. The author heard about the Center from her library liaison who now serves on the project's advisory group. This faculty member also took advantage of the work of the Center for New Media to provide a course Web site that would facilitate her students in capturing and incorporating information resources into their papers.

The decision to locate responsibility for the development and management of the University's institutional repository, Academic Commons, in the Center for Digital Research, proved to be very effective. Journals, conference proceedings, videos of presentations are natural candidates for the repository. Interactions with faculty about archiving research often lead to interest in CDRS's other services. Liaison librarians can offer faculty a wide range of services that go well beyond the traditional options of collection building and library instruction. A conversation in the History Department raised the question of how to provide access to senior history theses (Academic 
Commons is a natural home); the Slavic Studies Librarian applied for and received an NEH grant to run a Summer Institute using CDRS's Conference Services; a Humanities liaison librarian set up EndNote training for a summer seminar program, and was then able to connect the seminar leader with the video services unit so that a series of high interest seminar talks could be broadcast on YouTube. The seminar also asked for a collaboration site for sharing drafts of papers and the Center for Digital Research was able to work with the Library Information Technology Office to set up an alfresco instance for their use.

Academic Commons is the most visible part of the Library's long term, Fedora-based digital archive. Using a SAM-FS storage environment designed and managed by the Library Information Technology Office, but housed in the University's central data center, the long term archive has become key to the Library's management of its own digital collections and its ability to serve some of the broader digital archiving needs of the University. Researchers developing data management plans for NSF grant applications are able to call on the Academic Commons long term digital archive to meet some aspects of their data archiving and sharing plans.

National and international engagement continue to be high priorities for the Digital Programs group and for the Columbia Libraries generally, both in terms of giving back to the professional community and in sharing in the work of others to address key technology challenges. The Libraries belong to major technology organizations such as HathiTrust, DuraSpace, the National Digital Stewardship Alliance, the New Media Consortium and ORCID; Directors participate in national steering committees and advisory boards, and are frequently invited to consult and present at meetings. Programmers are committers to open source projects such as Fedora and Blacklight.

What have we learned from our work over the past several years? Certainly that investments in technical staff and in scalable infrastructure are critical to the Libraries' ability to provide the services that faculty and students want and need. That a critical mass of technology savvy staff with a variety of areas of expertise creates a stimulating and creative work environment where staff can develop and learn from each other. That scalable solutions and common systems are critical to our ability to accomplish a lot with a little.

The new organization has worked because staff at all levels are flexible and not territorial. Working together across unit boundaries has been a major learning experience for all staff, but particularly for the directors of each group who have developed a deeper understanding of each other's goals and approaches. For example, the fast-paced technology framework of the Center for New Media, with its focus on the immediate needs of this semester's classrooms, is quite different than the technology environment that must be built for long-term digital preservation. Directors today better understand these necessary differences and the work cultures that they engender. 
The Columbia Libraries are a distinctive example of collaboration and convergence, attracting and integrating independent and disparate programs and projects from across the University to advance an enhanced and innovative merging of information service ventures. By bringing together academic computing and research library and entrepreneurial vision, Columbia has created a valuable and powerful organizational strategy that significantly enhances productivity, service, and impact. 